\title{
Physiological, morphological and ecological traits drive desiccation resistance in north temperate dung beetles
}

\author{
Beatrice Nervo* ${ }^{*}$, Angela Roggero, Dan Chamberlain, Enrico Caprio, Antonio Rolando and Claudia Palestrini
}

\begin{abstract}
Background: Increasing temperatures and changes in precipitation patterns threaten the existence of many organisms. It is therefore informative to identify the functional traits that underlie differences in desiccation resistance to understand the response of different species to changes in water availability resulting from climate change. We used adult dung beetles as model species due to their importance to ecosystem services. We investigated: (i) the effect of physiological (water loss rate, water loss tolerance, body water content), morphological (body mass) and ecological (nesting behaviour) traits on desiccation resistance; (ii) the role of phylogenetic relatedness in the above associations; and, (iii) whether relatively large or small individuals within a species have similar desiccation resistance and whether these responses are consistent across species.
\end{abstract}

Results: Desiccation resistance decreased with increasing water loss rate and increased with increasing water loss tolerance (i.e. proportion of initial water content lost at the time of death). A lack of consistent correlation between these traits due to phylogenetic relatedness suggests that the relationship is not determined by a shared evolutionary history. The advantage of a large body size in favouring desiccation resistance depended on the nesting behaviour of the dung beetles. In rollers (one species), large body sizes increased desiccation resistance, while in tunnelers and dwellers, desiccation resistance seemed not to be dependent on body mass. The phylogenetic correlation between desiccation resistance and nesting strategies was significant. Within each species, large individuals showed greater resistance to desiccation, and these responses were consistent across species.

Conclusions: Resistance to desiccation was explained mainly by the dung beetles' ability to reduce water loss rate (avoidance) and to tolerate water loss (tolerance). A reduction in water availability may impose a selection pressure on body size that varies based on nesting strategies, even though these responses may be phylogenetically constrained. Changes in water availability are more likely to affect dweller species, and hence the ecosystem services they provide.

Keywords: Climate change, Drought, Effect traits, Nesting behaviour, Phylogenetic signal, Response traits, Scaled body mass

\section{Background}

Declines in insect abundance, biomass, and range are being reported worldwide, across insect orders, and from a spectrum of ecological guilds (e.g., [1, 2]). Increasing

*Correspondence: beatrice.nervo@unito.it

Department of Life Sciences and Systems Biology, University of Torino, Via

Accademia Albertina 13, 10123 Torino, Italy temperatures and changes in precipitation patterns represent two of the main threats to the persistence of many insect species [3], with low to mid latitude populations being most at risk [4]. Precipitation patterns are expected to become more variable under climate change, therefore species may have to tolerate longer periods between precipitation events, and the events themselves may be more extreme [5, 6]. 
Species and populations can respond to climate change by shifting their distribution and tracking optimum environments. However, in the absence of suitable habitat, or the capacity to relocate, species must adapt or go extinct [4]. Furthermore, marked species turnover could strongly affect ecosystem functioning [3, 7]. In grazed ecosystems, for example, dung beetles (Scarabaeoidea: Scarabaeidae, Aphodiidae, Geotrupidae) provide several ecosystem functions and services through the manipulation of livestock faeces for feeding and nesting processes [8-13]. In the Mediterranean area, characterized by high levels of dung beetle diversity and endemism [14-16], increasing temperature due to climate change is expected to induce a northward shift of thermophilous species (e.g. Scarabaeidae), more adapted to live in arid and warm conditions, that may replace the activity of mesophilous dung beetles that live in less extreme conditions (Aphodiidae, Geotrupidae). This rapid replacement of species is especially worrying at the southernmost extremities of Europe (e.g. the Italian peninsula) where the influx of a more thermophilous fauna would be probably more difficult because of the distance from the African continent [17]. Moreover, the effects of climate change on species' distributions may also be influenced by the immature phases of a dung beetle's life cycle (i.e. larvae, pupae) that might be even more sensitive to desiccation. Under these conditions, the distribution of resources-e.g. the extent and distribution of dung and suitable habitats-will be a key factor limiting species' responses to climate change. The dramatic abandonment of extensive historical grazing land, habitat degradation and use of medical veterinary products represent serious additional threats to dung beetle distribution changes [18].

Research effort with regards to climate change has mostly been focused on the consequences of increasing temperatures [19]. However, changes in water availability will also play a significant role [20], especially because it is known to be associated with insect distributions [7, 21] and is implicated, across taxa, in generating stronger selection gradients than temperature [22]. Although the complexity of natural systems presents fundamental limits to predictive modelling, understanding the interactions between environmental stressors and response traits, identifying which traits underpin a failure to adapt, and determining whether response traits change across species, can provide a useful first approximation as to how species will respond to climate change [23]. The effects of changes in water availability are mediated through physiological, morphological, and behavioural responses of organisms [ 7 , 24], thus the relationship among traits that drive these responses needs to be investigated. Physiological adaptations to desiccation resistance (i.e. the ability to resist losing water, measured as survival time) and the underlying traits (e.g. water loss rates - proportion of body water lost per hour, water loss tolerance - proportion of initial water content lost at the time of death, and water content - maximum water content stored) are suggested to be key traits under selection [25, 26], and their study will allow the understanding of how species will survive dry environments [27] through mechanistic models. In this context, dung beetles represent an excellent model group for the kind of physiological investigations required for such models [28-30], and they also represent an under-utilized opportunity to understand the relationship between morphological, ecological and physiological variation at intraspecific, interspecific and assemblage levels [30, 31].

Recent studies using trait-based approaches have shown the significance of traits such as body mass and nesting behaviour as response traits (i.e. traits related to individual fitness), in addition to effect traits (i.e. traits that impact on ecosystem functions) [32,33]. Dung beetle species show different feeding and nesting strategies, e.g. tunnelers dig tunnels below the dung mass in which they bury brood balls, dwellers brood their young inside the dung-mass itself, or at the soil-dung interface, and rollers transport dung balls some distance away from the dung pat before burial below the soil surface. The action of these different groups has been shown to have a complementary effect in space and time on dung removal rates and other functions such as bioturbation, nutrient cycling, plant growth enhancement and greenhouse gas emissions $[9,12,13,34-36]$, with larger species having a disproportionate effect on many ecosystem functions $[9,37]$. At the same time, nesting behaviour and body mass also represent important response traits to environmental variables such as water availability or temperature (e.g., [38-40]). The interplay between response traits and physiological traits requires more attention in dung beetle ecology, especially the role of variations in body water content and water loss rates in modulating desiccation resistance, and how these variables, in turn, are related to size or behavioural traits like nesting strategies [30]. The literature on this topic is mainly focused on African dung beetle communities [30], while, to our knowledge, little effort has been made in north temperate areas.

In this study, we used adult dung beetles to investigate: (i) physiological (i.e. water loss rate, water loss tolerance, water content), morphological (i.e. body mass), and ecological (i.e. nesting behaviour) traits that drive desiccation resistance; (ii) the role of phylogenetic relatedness in the above associations; and (iii) whether the effect of relative size within species on desiccation resistance is consistent across species or whether it is 
modulated by species identity. We expected that desiccation resistance would be mainly affected by low water loss rates and high water loss tolerance, but also by larger body sizes that reduce area-to-volume ratio $[38,41]$, thus improving water conservation [39]. We also expected that different nesting behaviours would result in species that may experience different environments and respond differently to water availability, with tunnelers and rollers being more tolerant to arid conditions.

\section{Results}

\section{General effects model}

Desiccation resistance was modulated both by physiological (i.e. water loss rate, water loss tolerance), morphological (i.e. body mass), and ecological (i.e. nesting behaviour) traits.

Desiccation resistance was explained by water loss rate, water loss tolerance, body mass (log), and nesting strategies. Desiccation resistance decreased with increasing water loss rate and increased with increasing water loss tolerance (Fig. 1). We found a significant interaction between body mass and nesting behaviour: desiccation resistance in rollers increased linearly with body mass, while it was not influenced by body mass in tunnelers and gradually decreased with body mass in dwellers (Table 1, Fig. 2).

The phylogenetic signal, defined by the variance of the standardized contrast values (VarContr, Table S1 in Additional file 2) was significant for desiccation resistance $(\mathrm{DR}=0.011)$, water loss rate $(\mathrm{WLR}=0.000)$, and nesting strategies $(\mathrm{NS}=0.357)$, while it was not
Table 1 Associations among physiological, reproductive and morphological traits

GLMER (sample size $=80$, species $=8$ )

DR NS * $\log B M+W L R+W L T+$ random factor (species), distribution $=$ Binomial

$\mathrm{AIC}=\mathbf{5 0 6 . 3}$

Variance explained $=0.89$

\begin{tabular}{llll}
\hline & Estimate \pm SE & z value & $\boldsymbol{p}$ \\
\hline Intercept & $-0.796 \pm 0.287$ & -2.777 & $* *$ \\
Rollers & $3.081 \pm 1.181$ & 2.614 & $* *$ \\
Tunnelers & $0.680 \pm 0.285$ & 2.380 & $*$ \\
Log BM & $-0.155 \pm 0.068$ & -2.292 & $*$ \\
WLR & $-71.831 \pm 5.372$ & -13.355 & $* * *$ \\
WLT & $0.005 \pm 0.001$ & 3.558 & $* * *$ \\
Rollers * log Body mass & $0.785 \pm 0.308$ & 2.554 & $*$ \\
Tunnelers * log Body mass & $0.156 \pm 0.069$ & 2.245 & $*$ \\
\hline
\end{tabular}

DR Desiccation Resistance is related to WLR Water Loss Rate, WLT Water Loss Tolerance, BM Body Mass, and NS Nesting Strategy. Fractional water content is not shown in the model because it was not significant. SE Standard Error. * $p<0.05 ; * * 0.01 ; * * 0<0.001$

significant for the other traits (Table S1 in Additional file 2). Phylogenetic independent contrasts (PicR) between desiccation resistance and the other traits showed a significant correlation between desiccation resistance and nesting strategies $(p=0.001$, Table S2 in Additional file 2), suggesting that the hypothesized relationship between these two traits may also be determined by the evolutionary history of species. (a)

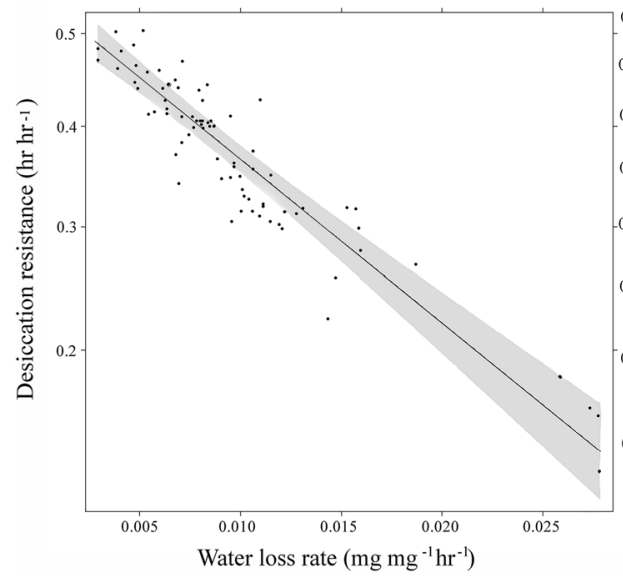

(b)

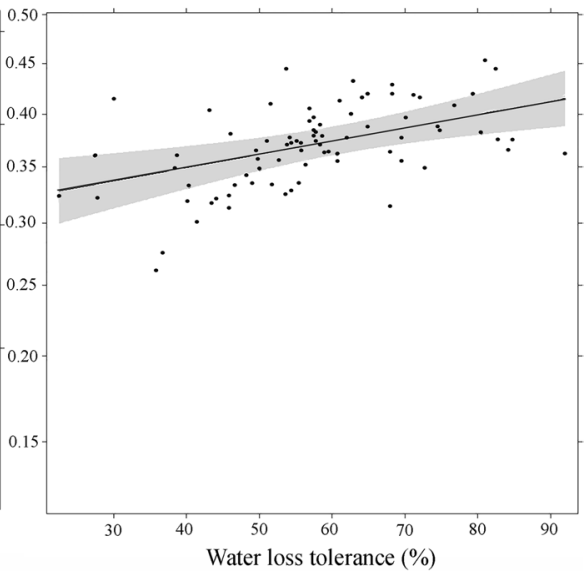

Fig. 1 Desiccation resistance of dung beetles is influenced by water loss rate, expressed as proportion of initial water content lost per hour (a), and water loss tolerance, expressed as the proportion of the initial water content that was lost at the time of death (b). 95\% confidence bands are displayed around each fitted line 


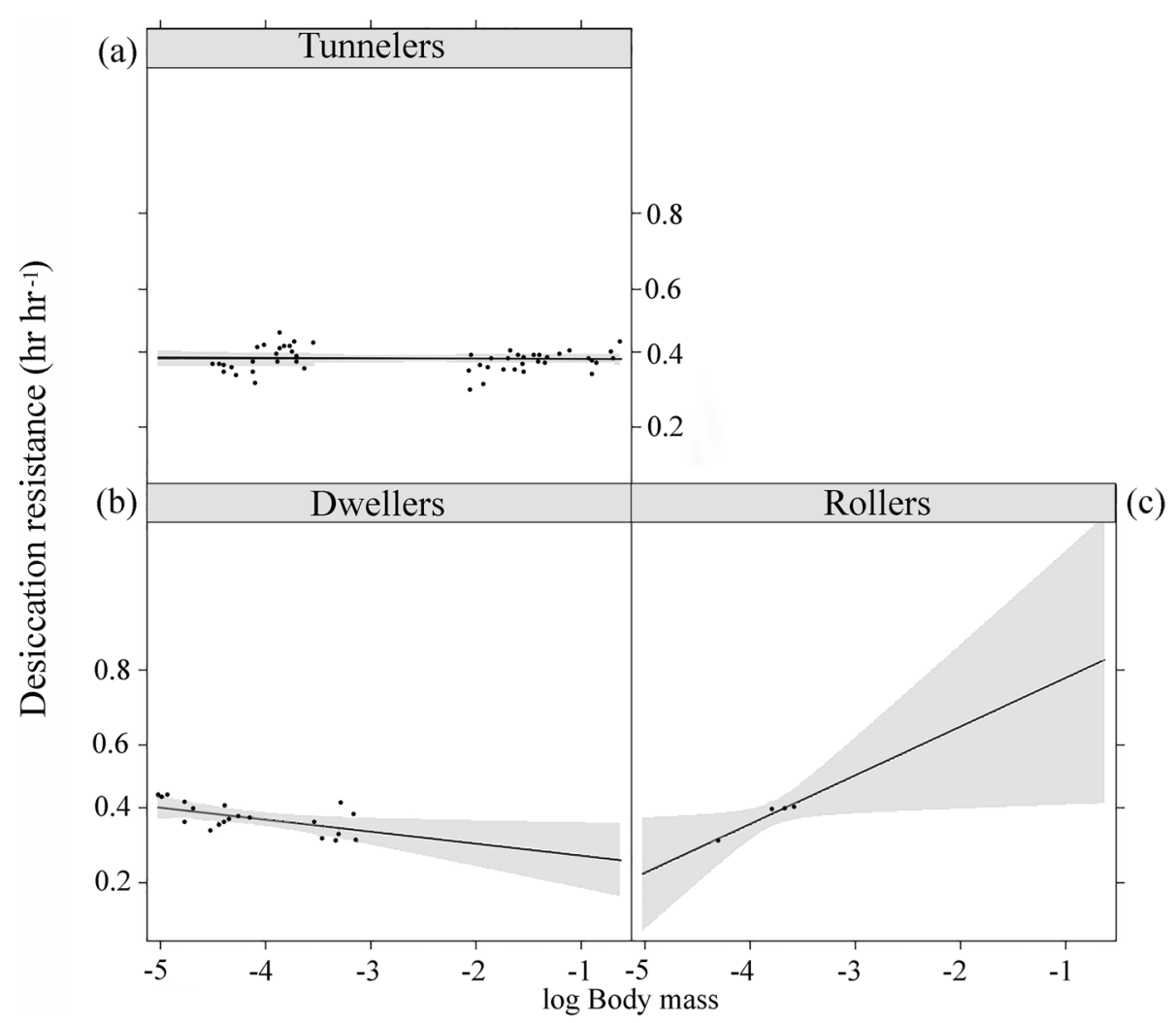

Fig. 2 Desiccation resistance is influenced by the interaction effect between body mass and nesting strategies: tunnelers (a), dwellers (b), and rollers (c). 95\% confidence bands are displayed around each fitted line

\section{Relative effects model}

Desiccation resistance depended on species, scaled body mass, scaled water loss rate, and scaled water loss tolerance (scaled variables were expressed using the respective average value for each species, see Methods for further details). Within each species, large individuals were more resistant to desiccation than smaller ones due to lower rates of water loss and higher water loss tolerance. Species significantly differed in desiccation resistance, with O. fracticornis, $O$. taurus, and S. schaefferi showing higher levels of resistance compared to the other species (Table 2, Fig. 3).

Since rollers were represented by only one species, we compared general and relative models that included S. schaefferi with those that did not include this species. The general and relative models that did not include $S$. schaefferi were qualitatively the same as the models including this species, thereby supporting the consistency of the results and confirming that the inclusion/ exclusion of this species did not affect our general conclusions (see models without S. schaefferi in Tables S1 and S2 in Additional file 1).

\section{Discussion}

A trait-based approach integrated with mechanistic physiological research and assemblage-level ecological studies can contribute not only to a better understanding of an ecologically important group such as dung beetles, but also to predicting the functional consequences of community changes on ecosystems. Our results provide support to our hypothesis that suggests water loss rates and water loss tolerance as important traits driving desiccation resistance in dung beetles. They also showed evidence that species with different nesting behaviours have different abilities to resist desiccation. The effect of large body mass in enhancing water conservation under stress conditions was especially evident at an intraspecific level.

\section{Effects of physiological, morphological and ecological traits on desiccation resistance}

Species distributions are often constrained by climatic tolerances, but the ability of species to adapt to changing environments may also be constrained by their evolutionary history [42]. Despite the limited number of species analyzed, the significant phylogenetic signal found in our study for desiccation resistance and water loss rate 
Table 2 Interspecific and intraspecific differences in desiccation resistance

\begin{tabular}{|c|c|c|c|}
\hline \multicolumn{4}{|c|}{ GLM (sample size $=80$, species $=8$ ) } \\
\hline \multicolumn{4}{|c|}{$\begin{array}{l}\text { DR scaled WLR + scaled WLT + scaled BM + Species, } \\
\text { distribution = Binomial }\end{array}$} \\
\hline \multicolumn{4}{|l|}{$A I C=497.97$} \\
\hline \multicolumn{4}{|c|}{ Variance explained $=0.87$} \\
\hline & Estimate \pm SE & $z$ value & $p$ \\
\hline Intercept & $-0.971 \pm 0.073$ & -13.267 & \\
\hline Scaled WLR & $-0.734 \pm 0.063$ & -11.682 & *** \\
\hline Scaled WLT & $0.411 \pm 0.101$ & 4.070 & *** \\
\hline Scaled BM & $0.163 \pm 0.066$ & 2.454 & * \\
\hline R. foetens & $0.009 \pm 0.102$ & 0.092 & NS \\
\hline B. rufa & $0.421 \pm 0.099$ & 4.234 & *** \\
\hline E. fulvus & $0.472 \pm 0.096$ & 4.891 & $* * *$ \\
\hline G. stercorarius & $0.524 \pm 0.079$ & 6.623 & $* * *$ \\
\hline O. fracticornis & $0.744 \pm 0.089$ & 8.337 & $* * *$ \\
\hline O. taurus & $0.687 \pm 0.915$ & 7.507 & $* * *$ \\
\hline S. schaefferi & $0.773 \pm 0.109$ & 7.075 & $* * *$ \\
\hline
\end{tabular}

DR Desiccation Resistance is related to WLR Water Loss Rate, WLT Water Loss Tolerance, and $B M$ Body Mass. Fractional water content is not shown because it was not significant. C. erraticus is the reference level. SE Standard Error, NS Not Significant. ${ }^{*} p<0.05 ;{ }^{* *} p<0.01 ;{ }^{* *} p<0.001$

suggests that physiological mechanisms to reduce water loss and increase resistance may be highly dependent on species' life histories.

Trait correlations due to phylogenetic relatedness may play an important role in shaping ecological adaptation [43]. However, a lack of consistent trait correlation between desiccation resistance, the three physiological traits (i.e. water loss rate, water loss tolerance, and fractional water content) and body mass suggests that the relationships between these traits are not strictly dependent on phylogenetic relatedness between the species [43].

Our study showed that the resistance of the investigated dung beetles to desiccation is explained mainly by their ability in reducing water loss rate (avoidance) and tolerating water loss (tolerance), as also shown in previous research [44, 45]. Here, water loss rate was shown to better predict desiccation resistance than water loss tolerance and water content. These results confirmed previous research on other model organisms (e.g. isopods, [46]) that showed how water loss rate is the main factor explaining resistance to desiccation. Moreover, we found that, after a certain percentage of water loss (about 50\%), a dung beetle's capability to resist desiccation decreased significantly. This percentage of water loss, that corresponds to reduced survival, seems to reflect a common pattern in arthropods; for example, fatal water loss is between 40 and $55 \%$ for isopods, ants, and weevils
[46-48], even though it can show higher values for other detritivorous taxa (e.g. earthworms 70-75\%, [49]). In our study, some tunneler species belonging to the Scarabaeinae (e.g. O. fracticornis, O. taurus, E. fulvus), showed a high percentage of water loss tolerance (64-70\%). The high values of water loss tolerance in these species indicates greater resistance to possible frequent dry periods under climate change.

Our study showed that body mass and nesting strategies are important morphological and ecological traits that influence desiccation resistance in adult dung beetles. Body mass has also been shown to be a key trait in influencing water balance strategies among species in other taxa, e.g. weevils, keratin beetles, isopods, flies [28, $47,50,51,52]$. Previous studies have shown that larger body size reduces the surface area-to-volume ratio [38, 41], thus improving water conservation. This may represent an advantage in terms of a reduced water loss rate [39], since body area does not increase linearly with body mass or volume. In line with previous studies, at an intraspecific level (i.e. relative effect models), large individuals seemed to be more resistant than small individuals and these responses were consistent across species. The intraspecific variability between individuals is at the base of natural selection and is important for the adaptation of organisms to environmental changes. However, when the effect of body mass on desiccation resistance was evaluated across species (i.e. general effect models), we found a significant interaction effect between body mass and functional groups based on nesting behaviour, suggesting that changing conditions in water availability of soil, dung or air may impose a selection pressure on body size that will vary in groups with different nesting strategies. In rollers, represented by only one species, large body sizes increased desiccation resistance, while in tunnelers and dwellers, desiccation resistance seemed not to be dependent on body mass. In tunnelers, the effects of large size in increasing desiccation resistance were not particularly evident, since large species such as G. stercorarius were characterized by lower desiccation resistance compared to smaller species such as O. fracticornis. In dwellers, we found a very slight tendency for desiccation resistance to increase with body mass which needs further investigation. These results may be explained by the fact that traits characterizing an individual can interact in complex, and sometimes opposite, ways by causing potential trait-specific constraints [24, 53]. For example, the advantageous effect of large body sizes with respect to resistance to desiccation may be counterbalanced by other traits that favour water loss. Differences in water loss rate may be linked to anatomical and morphological characteristics such as spiracle size, position and number which are highly variable within the Scarabaeoidea, but 


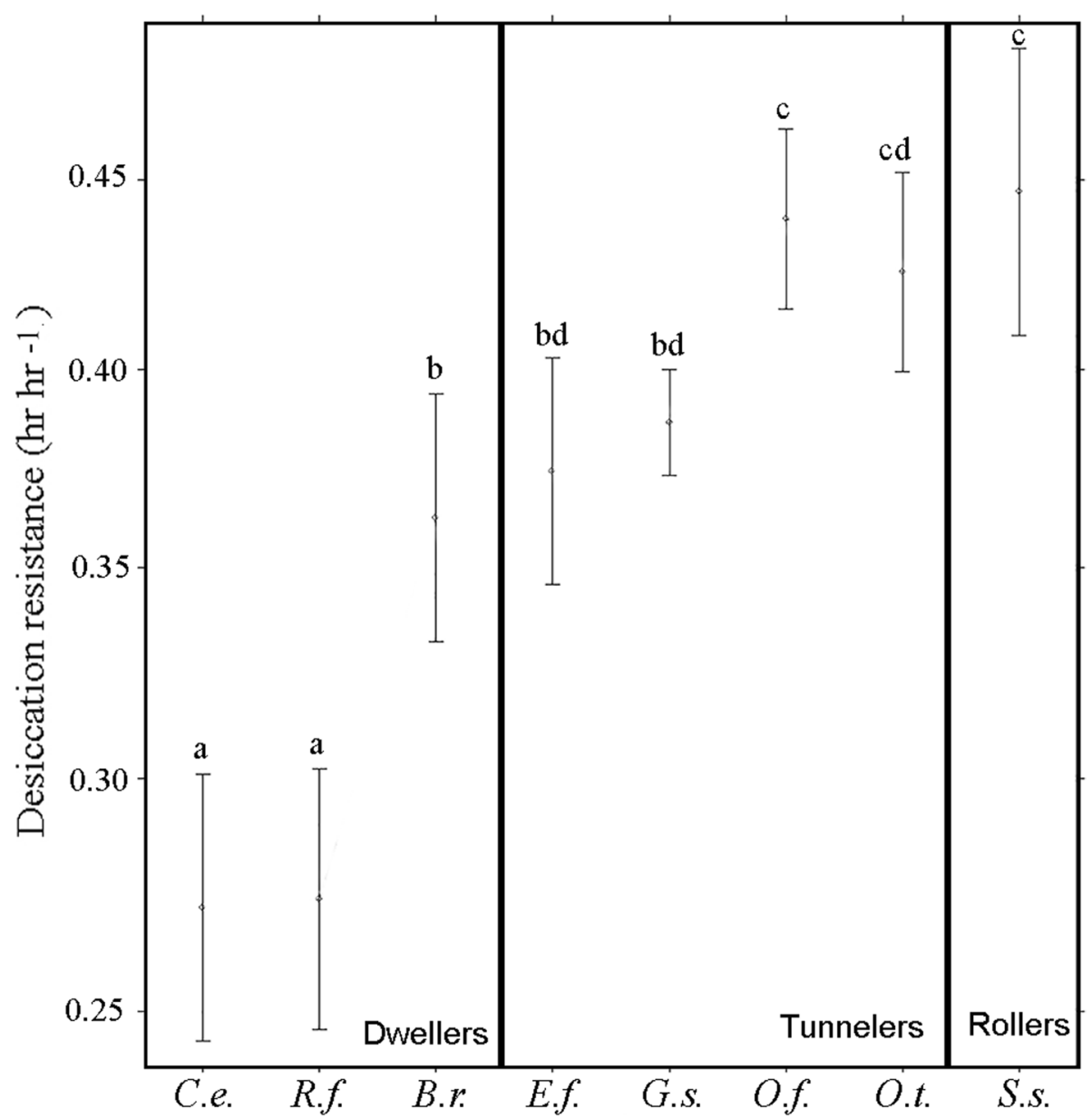

Fig. 3 Differences in desiccation resistance among the eight species. Letters over the error bars indicate the differences among species. Species have been grouped based on their nesting strategies into dwellers, tunnelers, and rollers. Abbreviations for species names means: C.e. $=C$. erraticus, R. foetens $=$ R.f. B.r. $=$ B. rufa, E.f. $=$ E. fulvus, G.s. $=$ G. stercorarius, O.f. $=$ O. fracticornis, O.t. $=$ O. taurus, S.s. $=$ S. schaefferi

that may be more similar in closely related species [54]. The ability of insects to conserve water and resist desiccation is also influenced by the movement of gas and water through the system of spiracular openings and tracheae [55] that may affect respiratory water loss.

Nesting strategy seemed to influence the physiological variations among the investigated species. The tunneler and roller species used in our study were generally more resistant to desiccation than dwellers because of their lower water loss rates and water loss tolerance. It is worth noting that the more resistant tunnelers belonged to the Scarabaeidae family, while dwellers belonged to the Aphodiidae family. Despite phylogenetic relatedness that may explain part of this relationship, species characterized by different nesting behaviours are more likely to experience different environments that lead to different responses to dry conditions. Dwellers spend most of their time inside the dung pat or in the dung-soil interface, where the humidity level is high (about $80 \%$ $\mathrm{RH}$ ), whereas tunnelers feed on dung, but they spend much time in the soil where they dig tunnels to lay their eggs. Larvae may also play an important role in determining different responses between nesting strategies: larvae in dung-ovipositing species may be more exposed to desiccation than soil-ovipositing species whose eggs are laid underground and inside dung-compacted reproductive balls. Future in-depth analyses considering a larger number of species and different life-cycle stages are crucial for making predictions about species responses to climate changes.

Our study showed that species belonging to Scarabaeidae such as $O$. fracticornis, O. taurus, and S. schaefferi are the most resistant to desiccation. In accord with [17], these species are more likely to respond to climate change by shifting their distributions northward and reaching new territories. However, [17] showed that O. taurus is 
expected to increase its current distribution under global warming, while $O$. fracticornis and $S$. schaefferi are likely to lose part of their current distribution.

\section{Caveats on interpretation}

There are a number of caveats that need to be made when interpreting the results. First, the water-related traits were measured gravimetrically in order to follow a standardized protocol [56] to enable comparative analysis. However, water in insects can be lost in different ways (i.e. transpiration through the cuticle, evaporation along open spiracles through the tracheal system, and excretion - $[39,44])$, and our approach does not take into consideration the different mechanisms underlying specific adaptation to reduce water loss pathways in different species. Second, we controlled water loss through excretion by starvation, as also suggested by the acclimation procedure in [56]. However, we should highlight that starvation may decrease metabolic rates, resulting in changes to cuticle and respiratory water loss [57]. Different metabolic rates and activities of insects during the experiment vary at the species level which is an extra-factor that may cause interspecific differences. This aspect can be taken into account in future studies, and appropriate alternatives to the acclimation procedure can be carried out by implementing the protocol in [56]. Third, we considered $70 \%$ as a relevant desiccation stressor for dung beetles since $85 \%$ humidity has been suggested to be an appropriate $\mathrm{RH}$ for insects inhabiting soil $[56,58]$. However, dung beetles are flying arthropods that for short periods can be exposed to lower humidity. For this reason, future studies should test different levels of humidity encompassing values from 0 to $70 \%$ to assess consistency of responses under different experimental conditions.

\section{Ecological implications}

Changes in community structure, and turnover of dung beetle species and functional traits may have consequences for the provisioning of ecosystem functions and services. Body size and nesting strategy have been shown to be crucial response traits in dung beetles [32, 33] that make species more prone to extinction, but at the same time they represent effect traits that influence the provisioning of ecosystem services such as soil nutrient cycling, dung removal and herbage growth (e.g. $[9,12,13,33])$. In our study, roller and tunneler species seemed to be the most resistant to desiccation, suggesting that changes in patterns of water availability, under a climate change context, probably will influence mostly dweller species with dung and soil-ovipositing nesting strategies. By spending most of their time inside the dung pat, dwellers may be more influenced by physical factors affecting dung, and this can explain the preference for closed habitats in these species [59].

Dwellers represent the main functional group in some areas such as the Alps, and even if their functional effect on dung removal, herbage growth and nutrient cycling seems less marked over a short time period compared to tunnelers, the tunnelers and dwellers seem similarly efficient for most functions, with differences based on the spatial and temporal scales over which the functions operate [12]. The replacement of species sensitive to water limitation (e.g. dwellers) by more resistant species (e.g. tunnelers or rollers) under a warming climate, may influence the provisioning of ecosystem services, especially if larger sized species, which have a relevant effect on ecosystem functioning, are more prone to local disappearance. Furthermore, warming temperature and lower humidity have been shown to decrease brood production and dung burial by tunnelers and rollers (e.g. Onthophagus taurus and Sisyphus rubrus) suggesting the impactful effect of climate change on the provisioning of ecosystem services [60, 61], but see [62]. This trait-based analysis raises questions for the direction of future research, for example, regarding possible ecological and evolutionary implications of the interactions between changes in water availability and warming temperatures, potential behavioural changes of tunnelers, rollers and dwellers in response to reductions in moisture conditions, and how these changes will affect trophic interactions.

\section{Conclusions}

In conclusion, resistance to desiccation was explained mainly by the dung beetles' ability to reduce water loss rate (avoidance) and to tolerate water loss (tolerance). Larger individuals within each species were more resistant than smaller individuals and these responses were consistent across species. However, when the effect of body mass on desiccation resistance was evaluated across species, we found a significant interaction between body mass and functional groups based on nesting behaviour, suggesting that changing conditions in water availability may impose a selection pressure on body size that varies in groups with different nesting strategies, even though these responses may be phylogenetically constrained. Changes in water availability are more likely to affect dweller species, and hence the ecosystem services they provide.

\section{Methods}

Species collection and trait measurements

Adult individuals of 8 different dung beetle species were collected in September 2019 in four different areas in the north-west of Italy (Piedmont) (Figure S3 in Additional file 1). Five species were collected from the pastures of 
the Istituto per le Piante da Legno e l'Ambiente (IPLA) in Torino $\left(45^{\circ} 05^{\prime} 18.5^{\prime \prime} \mathrm{N}, 7^{\circ} 44^{\prime} 28.5^{\prime \prime} \mathrm{E}, 300 \mathrm{~m}\right.$ a.s.l), one species from the pastures around Foresto $\left(45^{\circ} 08^{\prime} 32^{\prime \prime} \mathrm{N}\right.$ $7^{\circ} 07^{\prime} 14^{\prime \prime} \mathrm{E}$, Susa Valley, $470 \mathrm{~m}$ a.s.l.), four species from the pastures around Demonte $\left(44^{\circ} 18^{\prime} 59^{\prime \prime} \mathrm{N}, 7^{\circ} 17^{\prime} 59^{\prime \prime} \mathrm{E}\right.$, Stura Valley, $780 \mathrm{~m}$ a.s.l.), and two species from the high altitude pastures around the sanctuary of S. Anna di Vinadio $\left(44^{\circ} 13^{\prime} 55.2^{\prime \prime} \mathrm{N}, 7^{\circ} 06^{\prime} 18^{\prime \prime} \mathrm{E}\right.$, Stura Valley, $2035 \mathrm{~m}$ a.s.l.). Four species were present in more than one area (G. stercorarius and O. fracticornis in Torino and S. Anna di Vinadio; O. taurus and E. fulvus in Torino and Demonte). Species, collected mainly in cattle dung, represented three different functional groups defined according to nesting behaviour: tunnelers, dwellers, and rollers (Table 3, to note that only one species belonged to rollers). These species are commonly found in cattle dung, but they are able to utilize a wide range of dung coming from different herbivorous mammals such as horse and sheep dung [63]. Sex ratio was approximately 50:50 for each species.

We followed the trait-based protocol suggested by [56] for standardized measurement of traits in terrestrial invertebrates. The explicit guidelines provided by the authors have the potential to serve as a basis for comparative studies using functional traits [66]. Before exposing beetles to dry conditions and measuring desiccation resistance, individuals were acclimatized by replenishing any possible water deficit in order to start the experimental measurements with approximately the maximum possible body water content. This pre-treatment procedure was done without food to induce animals to empty their gut and reduce faecal production, in order to avoid any change in body mass not related to water loss. Beetles were kept isolated in small cylinders (diameter $2 \mathrm{~cm}$, height $3 \mathrm{~cm}$ ) placed in a closed glass box $(40 \times 20 \times 20 \mathrm{~cm})$, on top of a $3 \mathrm{~cm}$ layer of moist floral foam for 3 days, ensuring constant conditions of 100\% relative humidity $(\mathrm{RH})$. The level of humidity inside the box was measured with humidity data loggers (Plug \& $\left.\operatorname{Track}^{\mathrm{TM}}\right)$. The laboratory was kept at a temperature of $20{ }^{\circ} \mathrm{C}$ for the whole acclimation period (average temperature: $20.4 \pm 0.3^{\circ} \mathrm{C}$ ) under a12:12 h photocycle. The cylinders were open at both sides which were covered with a nylon mesh cloth (width $0.5 \mathrm{~mm}$ ) to prevent beetles from escaping, but allowing an adequate airflow in the cylinder. Based on the abundance of each species, one, two or three individuals were kept in the glass container $(100 \%$ $\mathrm{RH})$ after the starvation period as a control; none of these controls died before the end of the desiccation resistance measurements.

Dung beetles were exposed to moderate dry conditions, approximately $70 \% \mathrm{RH}$ (average value: $69.4 \pm 1.3 \%$ ), to record survival time, water loss rate, and percentage of fatal water loss. This $\mathrm{RH}$ value was chosen to represent a moderate stress condition considering that, on average, cattle dung has a relative humidity of $80 \%$, and that $91-93 \%$ is the threshold above which arthropods (e.g. terrestrial isopods, beetles) are able to absorb water vapour $[67,68]$. The humidity level of $70 \%$ RH was reached using a glycerol-water solution in volume concentration of $48 \%$ (as per [46]. The level of humidity inside the cylinders was measured with humidity data loggers. Plastic glasses $(200 \mathrm{ml})$ were filled with $80 \mathrm{ml}$ of glycerol solution. In each glass, a platform made of steel wire was placed about $1 \mathrm{~cm}$ above the solution's surface; the cylinder containing the animal was then placed on this platform and the glass closed with a plastic cover. The platform allowed air exchange between the solution and the cylinder inside the glass. The temperature range for the experimental period was $21-22{ }^{\circ} \mathrm{C}$.

Table 3 Species collected in the four sampling areas

\begin{tabular}{|c|c|c|c|c|c|c|}
\hline \multirow[t]{2}{*}{ Family } & \multirow[t]{2}{*}{ Species } & \multirow[t]{2}{*}{ Nesting strategy } & \multicolumn{4}{|c|}{ Sampling areas } \\
\hline & & & Torino & Foresto & Demonte & $\begin{array}{l}\text { S. Anna di } \\
\text { Vinadio }\end{array}$ \\
\hline Geotrupidae & Geotrupes stercorarius (Linnaeus, 1758) & Tunneler & 8 & & & 30 \\
\hline \multirow[t]{4}{*}{ Scarabaeidae } & Onthophagus fracticornis (Preyssler, 1790) & Tunneler & 9 & & & 30 \\
\hline & Onthophagus taurus (Schreber, 1759) & Tunneler & 9 & & 7 & \\
\hline & Euoniticellus fulvus (Goeze, 1777) & Tunneler & 7 & & 8 & \\
\hline & Sisyphus schaefferi (Linnaeus, 1758) & Roller & & 8 & & \\
\hline \multirow[t]{3}{*}{ Aphodiidae } & Rhodaphodius foetens (Fabricius, 1787) & Dweller & 7 & & & \\
\hline & Colobopterus erraticus (Linnaeus, 1758) & Dweller & & & 7 & \\
\hline & Bodilopsis rufa (Moll, 1782) & Dweller & & & 7 & \\
\hline
\end{tabular}

Dwellers include both dung- and soil-ovipositing species. Dweller species with a soil-ovipositing behaviour are C. erraticus [64,65]. The number of individuals of each species used in the experiment is specified. The overall sample size was 137 individuals 
We measured 7-39 individuals per species depending on the abundance of the animals collected in the field (Table 3). Before exposing the beetles to dry conditions, individuals in each cylinder were weighed to record their initial fresh mass using an analytical balance (Precisa $125 \mathrm{~A}, 0.1 \mathrm{mg}$ ). We recorded changes in individual body mass $(\mathrm{mg})$ every $3 \mathrm{~h}$ during the day (9:00 am, 12:00 am, 3:00 pm, 6:00 pm). Before weighing the dung beetles, we checked if they were alive by disturbing them gently with a soft brush or by flipping them with tweezers. By weighing the cylinders containing the beetles at regular times, we were able to register weight changes, and, at the same time, minimize disturbance, as also shown by [46]. The test was conducted for $96 \mathrm{~h}$, after which we ended the experiment even if some individuals were still alive, to avoid other potential stress factors, such as starvation, influencing the measurements [56]. Animals that were still alive at the end of the experiment were killed by exposing them to ethyl acetate, an efficient method used in entomology [69]. Dead animals were weighed and frozen for further morphological analyses.

We measured desiccation resistance and the three underlying physiological traits (i.e. water loss rate, fatal water loss, and water content) only on individuals that died during the experiment (Table 4). Desiccation resistance was estimated as survival time, which refers to the time that dry conditions can be tolerated before an organism dies. Survival time of each individual was calculated as the number of hours an organism survives in proportion to the total number of hours of the experiment, expressed as a value between $0(0 \mathrm{~h} / 96 \mathrm{~h})$ and 1 (96 h/96 h). If individuals died overnight, the median of the values (in hours) of the last measurement in the afternoon (e.g. 6:00 pm) and the first in the morning (e.g. 9:00 am) was used to calculate desiccation resistance, according to [56]. Water loss rate describes the rate of water loss from an individual over a given period of time (proportion of initial water content lost per hour); it was estimated as the slope of the linear regression between water mass and time and expressed as the proportion of initial body water content that was lost per unit of time $\left(\mathrm{mg} \mathrm{mg}^{-1} \mathrm{~h}^{-1}\right)$ [46]. Water loss tolerance was expressed as the proportion of the initial water content that was lost at the time of death, i.e. [(initial wet body mass - final wet body mass)/ initial water content] $\times 100$. If the individual died overnight, we used the average value of body mass of the last measurement in the afternoon and the first in the morning. Water content, which is the maximum water content that an organism is able to store, was expressed as a fractional water content (initial water content / dry body mass). Potential effects of collinearity among physiological predictor variables were calculated using the pairplot combined with correlation coefficients in $\mathrm{R}$ [70]. Water loss rate, water loss tolerance, fractional water content, and body mass were not found to be correlated with each other, allowing us to use them as covariates in the models (Fig. S4 in Additional file 1).

Once the experiment was over, we measured the dry body mass of each individual. To measure the dry body mass (hereafter body mass), the insects were dried in the oven (Binder FD) at $25^{\circ} \mathrm{C}$ for $24 \mathrm{~h}$ and weighed until the weight was constant between subsequent measurements (every $12 \mathrm{~h})$.

\section{Statistical analyses}

We used two different statistical approaches: the first was used to investigate morphological, ecological and physiological traits that influence desiccation resistance, while the second was used to test if relatively large and small individuals within species have similar desiccation resistance and whether these responses are consistent across species.

The general effect of physiological (water loss rate, water loss tolerance, and fractional water content), morphological (body mass), and ecological (nesting

Table 4 Average trait values and standard deviations for each species

\begin{tabular}{|c|c|c|c|c|c|c|}
\hline Species & $\begin{array}{l}\text { Dead individuals/ } \\
\text { Total }\end{array}$ & $\mathrm{BM} \pm \mathrm{SD}(\mathrm{mg})$ & $\mathrm{DR} \pm \mathrm{SD}\left(\mathrm{hr} h r^{-1}\right)$ & $\begin{array}{l}\text { WLR } \pm S D(m g ~ m g \\
\left.h^{-1}\right)\end{array}$ & WLT \pm SD (\%) & $\begin{array}{l}\text { fWC } \pm S D \\
\left(\mathrm{mg} \mathrm{mg}^{-1}\right)\end{array}$ \\
\hline G. stercorarius & $31 / 38$ & $247.787 \pm 120.305$ & $0.646 \pm 0.160$ & $0.008 \pm 0.002$ & $50.934 \pm 8.631$ & $2.177 \pm 3.212$ \\
\hline O. fracticornis & $12 / 39$ & $18.158 \pm 5.334$ & $0.755 \pm 0.199$ & $0.007 \pm 0.003$ & $70.661 \pm 18.170$ & $4.286 \pm 1.528$ \\
\hline O. taurus & $8 / 16$ & $21.175 \pm 5.926$ & $0.768 \pm 0.193$ & $0.008 \pm 0.004$ & $64.465 \pm 15.513$ & $2.063 \pm 0.694$ \\
\hline E. fulvus & $8 / 15$ & $18.388 \pm 3.966$ & $0.671 \pm 0.228$ & $0.012 \pm 0.006$ & $69.671 \pm 6.255$ & $2.421 \pm 1.303$ \\
\hline S. schaefferi & $4 / 8$ & $22.350 \pm 6.267$ & $0.766 \pm 0.125$ & $0.005 \pm 0.002$ & $47.342 \pm 16.704$ & $2.958 \pm 1.575$ \\
\hline R. foetens & $7 / 7$ & $36.643 \pm 5.259$ & $0.393 \pm 0.145$ & $0.014 \pm 0.006$ & $54.812 \pm 3.313$ & $2.210 \pm 0.495$ \\
\hline C. erraticus & $7 / 7$ & $8.229 \pm 1.497$ & $0.393 \pm 0.121$ & $0.018 \pm 0.007$ & $62.011 \pm 13.101$ & $2.398 \pm 0.775$ \\
\hline B. rufa & $7 / 7$ & $13.014 \pm 1.483$ & $0.634 \pm 0.126$ & $0.009 \pm 0.003$ & $50.173 \pm 15.636$ & $2.335 \pm 1.620$ \\
\hline
\end{tabular}

We specified the number of animals that died during the experiment, BM Body Mass, DR Desiccation Resistance, WLR Water Loss Rate, WLT Water Loss Tolerance and fWC Fractional Water Content with the respective SD Standard Deviations 
behaviour) traits on desiccation resistance was tested by using Generalized Linear Mixed effects Models (GLMMs) with a Binomial distribution. Visual inspection of frequency distributions and Shapiro-Wilk tests confirmed the non-normality of errors. Species identity (8 different species) was specified as a random effect to account for non-independence of conspecific individuals, where intercepts were allowed to vary between species. We fitted the models in R package "lme4" [71], with the formula:

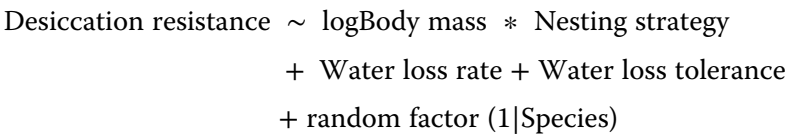

Henceforth, this is referred to as the general effects model. We checked for interactions and non-linear terms between the covariates. If the interaction effect was not significant, the term was added to the model as an additive factor. We removed non-significant terms from the model (i.e. fractional water content).

In the second approach, we used generalized linear models (GLM) with a Binomial distribution to verify whether desiccation resistance varied in response to individuals with different body size, water loss rate and water loss within each species and if these responses were consistent across species. The variations in body mass, water loss rate and water loss within each species were expressed as scaled values, e.g. (body mass of the individual - average body mass of the species)/ average body mass of the species. In this way, we considered how relative intraspecific body mass (i.e. relatively large or small individuals of the same species), water loss rate and tolerance (i.e. individuals of the same species with high or low water loss rate and tolerance) affected desiccation resistance, and whether the within-species pattern was also consistent across species. We modelled desiccation resistance of all individuals as a function of species, scaled body mass, scaled water loss rate and scaled water loss tolerance. Interactions and non-linear terms were initially tested but were not significant, thus all variables were included as additive factors via the formula:

$$
\begin{aligned}
\text { Desiccation resistance } & \sim \text { Species }+ \text { Scaled body mass } \\
& + \text { Scaled Water loss rate } \\
& + \text { Scaled Water loss tolerance }
\end{aligned}
$$

Henceforth, this is referred to as the relative effects model. As above, we removed non-significant terms from the model (i.e. fractional water content).

Since only one species belonged to the rollers, we repeated the models for both approaches without $S$. schaefferi to assess whether the inclusion of this species made a difference to the general conclusions.

\section{Phylogenetic signal and relationships between traits}

Fitting a species as a random effect implicitly assumes a constant degree of independence between species (i.e. that of the phylogenetic relatedness is trivial). We assessed the possible effect of phylogeny on our results by constructing a phylogenetic tree based on mitochondrial COI sequence (see Table S3 in Additional file 2 for the list of the accession numbers) and testing the relationship among traits. The COI sequence was chosen as a reliable proxy to define the relationships among coleopteran taxa, according to [72]. Both Maximum Parsimony (MP) and Maximum Likelihood (ML) approaches were used to evaluate the evolutionary history of the species (for the details of the molecular analysis, see Box S4 in Additional file 2). The ML analysis options were set according to the best fit value (Table S5 in Additional file 2), and the evolutionary divergence between sequences was estimated (Table S6 in Additional file 2). The resulting trees were compared and the phylogenetic relationships among the species were examined (Figure S7 in Additional file 2). Then, a reduced matrix was built, in which only a terminal node for each ingroup species was included (Table S3 in Additional file 2) to build a ML tree (Figure S8 in Additional file 2) and to test the phylogenetic signal of the traits. The phylogenetic signal is the tendency of related species to resemble each other more than species drawn at random from the same tree. All the molecular phylogenetic analyses were conducted using MEGA v10 [73].

The phylogenetic signal was calculated using the software PhyloCom v4.2 [74]. In the analysis, a matrix of the mean values of each trait for each species and the reduced ML tree (Fig S8 in Additional file 2) were used to correlate the eight taxa and six traits (i.e., desiccation resistance, water loss rate, water loss tolerance, fractional water content, dry body mass and nesting strategy), based on the phylogenetic relationships of these taxa. A detailed description of the analysis used to calculate the variance of the standardized contrasts (VarContr, Table S1 in Additional file 2) and the phylogenetic independent contrasts (PicR, Table S2 in Additional file 2) can be found in Box S9 in Additional file 2. The PicR method was used to estimate the correlation among traits due to phylogenetic relatedness.

\footnotetext{
Abbreviations

DR: Desiccation resistance; WLR: Water loss rate; WLT: Water loss tolerance; fWC: Fractional water content; NS: Nesting strategies; SE: Standard Error; GLM: Generalized linear models; GLMM: Generalized Linear Mixed effects Models; G.s: Geotrupes stercorarius; O.f:: Onthophagus fracticornis; O.t.: Onthophagus taurus; E.f.: Euoniticellus fulvus; R.f.: Rhodaphodius foetens; C.e.: Colobopterus erraticus; B.f.: Bodilopsis rufa.
} 


\section{Supplementary Information}

The online version contains supplementary material available at https://doi. org/10.1186/s40850-021-00089-3.

Additional file 1: Supporting information on methods. Table S1. Associations among physiological, reproductive and morphological traits without including S. schaefferi which is the only species belonging to rollers. Table S2. Interspecific and intraspecific differences in desiccation resistance without including $S$. schaefferi which is the only species belonging to rollers. Figure $\mathbf{S 3}$. The four sampling areas where the dung beetle species were collected. Figure S4. Pairplot of all response variables.

Additional file 2: Phylogenetic analysis results. Table S1. The variance of the standardized contrasts (VarContr) value define the amount of phylogenetic signal for each trait. Table S2. Independent contrast correlations (traits 2 and higher vs. trait 1). Table S3. Accession codes of the COI-5P sequences used in the phylogenetic analysis. The sequences marked by the asterisk were used in the phylogenetic signal analysis. Box S4. The phylogenetic analysis. Table S5. Maximum Likelihood fits of 24 different nucleotide substitution models. Table S6. Estimates of Evolutionary Divergence between Sequences. Figure S7. The ML tree with the highest log likelihood (-3191.7887). Figure S8. The bootstrap tree from the ML tree with the highest log likelihood (-2731.88). Box S9. The Phylogenetic signal.

\section{Acknowledgements}

We are really grateful to Alfredo Santovito who shared his lab and instruments. We are also thankful to Susanne Jähnig and Matteo Negro for help and logistical support. A special thanks to Giorgio Rosestolato and Margherita Penna who carried out the morphological measurements of dung beetles. The authors declare no conflicts of interest.

\section{Authors' contributions}

This work was conducted by the six authors listed. BN and CP conceived the experiment. BN and AR1 carried out the experiment. BN performed statistical analysis with the support of EC, DC, and AR1. BN wrote the manuscript. DC and AR2 contributed to the final version of the manuscript. $\mathrm{CP}$ and AR2 supervised the project. All the authors read and approved the manuscript.

\section{Funding}

Not applicable.

\section{Availability of data and materials}

The datasets used and/or analysed during the current study are available from the corresponding author on reasonable request.

\section{Declarations}

Ethics approval and consent to participate

Not applicable.

\section{Consent for publication}

Not applicable.

\section{Competing interests}

The authors declare that they have no competing interests.

Received: 21 November 2020 Accepted: 23 August 2021

Published online: 09 September 2021

\section{References}

1. van Klink R, Bowler DE, Gongalsky KB, Swengel AB, Gentile A, Chase JM. Meta-analysis reveals declines in terrestrial but increases in freshwater insect abundances. Science. 2020;368(6489):417-20.
2. Montgomery GA, Dunn RR, Fox R, Jongejans E, Leather SR, Saunders ME, Shorthall CR, Tingley MW, Wagner DL. Is the insect apocalypse upon us? How to find out. Biol Conserv. 2020:241:108327.

3. Cardoso P, Barton PS, Birkhofer K, Chichorro F, Deacon C, Fartmann T, Fukushima CS, et al. Scientists' warning to humanity on insect extinctions. Biol Conserv. 2020;242:108426.

4. Kellermann V, van Heerwaarden B. Terrestrial insects and climate change: adaptive responses in key traits. Physiol Entomol. 2019;44:99-115.

5. Bindoff NL, Stott PA, Achuta Rao KM, Allen MR, Gillett N, Gutzler D, Hansingo K et al. Detection and attribution of climate change: from global to regional. In: Stocker TF, Qin D, Plattner GK, Tignor M, Allen SK, Doschung J, Nauels A, et al., editors. Climate change 2013: the physical science basis. Contribution of Working Group I to the fifth assessment report of the Intergovernmental Panel on Climate Change. Cambridge and New York: Cambridge University Press; 2013. p. 867-952.

6. Smith SJ, Edmonds J, Hartin C, Mundra A, Calvin K. Near-term acceleration in the rate of temperature change. Nat Clim Change. 2015;5:333-6.

7. Scheffers BR, De Meester L, Bridge TCL, Hoffmann AA, Pandolfi JM, Corlett RT, Butchart SHM, et al. The broad footprint of climate change from genes to biomes to people. Science. 2016;354(6313):aaf7671.

8. Nichols E, Spector S, Louzada J, Larsen T, Amezquita S, Favila ME, Network TSR. Ecological functions and ecosystem services provided by Scarabaeinae dung beetles. Biol Conserv. 2008;141:1461-74.

9. Nervo B, Tocco C, Caprio E, Palestrini C, Rolando A. The effects of body mass on dung removal efficiency in dung beetles. PLoS One. 2014;9(9):e107699.

10. Tixier T, Bloor JM, Lumaret JP. Species-specific effects of dung beetle abundance on dung removal and leaf litter decomposition. Acta Oecol. 2015;69:31-4.

11. Manning P, Slade EM, Beynon SA, Lewis OT. Functionally rich dung beetle assemblages are required to provide multiple ecosystem services. Agric Ecosyst Environ. 2016;218:87-94.

12. Nervo B, Caprio E, Celi L, Lonati M, Lombardi G, Falsone G, lussig G, Palestrini C, Said-Pullicino D, Rolando A. Ecological functions provided by dung beetles are interlinked across space and time: evidence from $15 \mathrm{~N}$ isotope tracing. Ecology. 2017;98:433-46.

13. Piccini I, Arnieri F, Caprio E, Nervo B, Pelissetti S, Palestrini C, Roslin T, Rolando A. Greenhouse gas emissions from dung pats vary with dung beetle species and with assemblage composition. PloS One. 2017;12(7):e0178077.

14. Lumaret JP, Lobo JM. Geographic distribution of endemic dung beetles (Coleoptera, Scarabaeoidea) in the Western Palaearctic region. Biodivers Lett. 1996;3:192-9.

15. Lobo JM, Martín-Piera F. Searching for a predictive model for species richness of Iberian dung beetle based on spatial and environmental variables. Conserv Biol. 2002;16:158-73.

16. Lobo JM, Lumaret JP, Jay-Robert P. Modelling the species richness distribution of French dung beetles (Coleoptera, Scarabaeidae) and delimiting the predictive capacity of different groups of explanatory variables. Glob Ecol Biogeogr. 2002;11:265-77.

17. Dortel E, Thuiller W, Lobo JM, Bohbot H, Lumaret JP, Jay-Robert P. Potential effects of climate change on the distribution of Scarabaeidae dung beetles in Western Europe. J Insect Conserv. 2013:17:1059-70.

18. IUCN. The IUCN Red List of Threatened Species, version 2016-1. 2016. http://www.iucnredlist.org.

19. Pintor AF, Schwarzkopf $L$, Krockenberger AK. Hydroregulation in a tropical dry-skinned ectotherm. Oecologia. 2016;182:925-31.

20. McCain CM, Colwell RK. Assessing the threat to montane biodiversity from discordant shifts in temperature and precipitation in a changing climate. Ecol Lett. 2011;14:1236-45.

21. Olfert O, Weiss RM, Soroka JJ, Elliott RH. Bioclimatic approach to assessing factors influencing shifts in geographic distribution and relative abundance of two flea beetle species (Coleoptera: Chrysomelidae) in North America. Can Entomol. 2018;150:66-79.

22. Siepielski AM, Morrissey MB, Buoro M, Carlson SM, Caruso CM, Clegg SM, Coulson T, et al. Precipitation drives global variation in natural selection. Science. 2017;355:959-62.

23. Pearson RG, Dawson TP. Predicting the impacts of climate change on the distribution of species: are bioclimate envelope models useful? Glob Ecol Biogeogr. 2003;12:361-71. 
24. Clusella-Trullas S, Blackburn TM, Chown SL. Climatic predictors of temperature performance curve parameters in ectotherms imply complex responses to climate change. Am Nat. 2011;177:738-51.

25. Bujan J, Yanoviak SP, Kaspari M. Desiccation resistance in tropical insects: causes and mechanisms underlying variability in a Panama ant community. Ecol Evol. 2016;6:6282-91.

26. Weldon CW, Boardman L, Marlin D, Terblanche JS. Physiological mechanisms of dehydration tolerance contribute to the invasion potential of Ceratitis capitate (Wiedemann)(Diptera: Tephritidae) relative to its less widely distributed congeners. Front Zool. 2016;13:15.

27. Gibbs AG, Fukuzato F, Matzkin LM. Evolution of water conservation mechanisms in Drosophila. J Exp Biol. 2003;206:1183-92.

28. Chown SL, Scholtz CH, Klok CJ, Joubert FJ, Coles KS. Ecophysiology, range contraction and survival of a geographically restricted African dung beetle (Coleoptera: Scarabaeidae). Funct Ecol. 1995;9:30-39.

29. Davis ALV, Frolov AV, Scoltz CH. The African dung beetle genera. Protea Book House: Pretoria; 2008.

30. Chown SL, Klok J. The ecological implications of physiological diversity in dung beetles. In: Simmons LW, Ridsdill-Smith TJ, editors. Ecology and evolution of dung beetles. Oxford: Wiley; 2011. p. 200-219.

31. Gaston KJ, Blackburn TM. Pattern and process in macroecology. Oxford: Blackwell Science; 2000

32. Larsen TH, Lopera A, Forsyth A. Understanding trait-dependent community disassembly: dung beetles, density functions, and forest fragmentation. Conserv Biol. 2008;22:1288-98.

33. Piccini I, Nervo B, Forshage M, Celi L, Palestrini C, Rolando A, Roslin T. Dung beetles as drivers of ecosystem multifunctionality: are response and effect traits interwoven? Sci Total Environ. 2017;616:1440-8.

34. Beynon SA, Mann DJ, Slade EM, Lewis OT. Species-rich dung beetle communities buffer ecosystem services in perturbed agro-ecosystems. J Appl Ecol. 2012:49:1365-72.

35. Braga RF, Korasaki V, Andresen E, Louzada J. Dung beetle community and functions along a habitat-disturbance gradient in the Amazon: a rapid assessment of ecological functions associated to biodiversity. PLoS One. 2013;8(2):e57786

36. Braga RF, Carvalho R, Andresen E, Anjos DV, Alve-Silva E, Louzada J. Quantification of four different post-dispersal seed deposition patterns after dung beetle activity. J Trop Ecol. 2017;33:407-10.

37. Rosenlew $\mathrm{H}$, Roslin T. Habitat fragmentation and the functional efficiency of temperate dung beetles. Oikos. 2008;117:1659-66.

38. Chown SL, Pistorius P, Scholtz CH. Morphological correlates of flightlessness in southern African Scarabaeinae (Coleoptera: Scarabaeidae): testing a condition of the water-conservation hypothesis. Can J Zool. 1998;76:1123-33.

39. Hadley NF. Water relations of terrestrial arthropods. San Diego: CUP Archive; 1994

40. Macagno AL, Zattara EE, Ezeakudo O, Moczek AP, Ledón-Rettig CC. Adaptive maternal behavioral plasticity and developmental programming mitigate the transgenerational effects of temperature in dung beetles. Oikos. 2018;127(9):1319-29.

41. Schmidt-Nielsen K, Knut SN. Scaling: why is animal size so important? New York: Cambridge University Press. 1984.

42. Kellermann V, Overgaard J, Hoffmann AA, Fløjgaard C, Svenning JC, Loeschcke V. Upper thermal limits of Drosophila are linked to species distributions and strongly constrained phylogenetically. PNAS. 2012;109:16228-33.

43. Kellermann V, Overgaard J, Loeschcke V, Kristensen TN, Hoffmann AA. Trait associations across evolutionary time within a Drosophila phylogeny: correlated selection or genetic constraint? PloS One. 2013;8:e72072

44. Edney EB. Water balance. In: Land arthropods. Berlin: Springer; 1977.

45. Addo-Bediako A, Chown SL, Gaston KJ. Revisiting water loss in insects: a large scale view. J Insect Physiol. 2001;47:1377-88.

46. Dias AT, Krab EJ, Mariën J, Zimmer M, Cornelissen JH, Ellers J, Wardle DA, Berg MP. Traits underpinning desiccation resistance explain distribution patterns of terrestrial isopods. Oecologia. 2013;172:667-77.

47. Hood WG, Tschinkel WR. Desiccation resistance in arboreal and terrestrial ants. Physiol Entomol. 1990;15:23-35.
48. Chown SL. Desiccation resistance in 6 sub-antarctic weevils (Coleoptera, (Curculionidae) — humidity as an abiotic factor influencing assemblage structure. Funct Ecol. 1993;7:318-25.

49. Roots BI. The water relations of earthworms: II. Resistance to desiccation and immersion, and behaviour when submerged and when allowed a choice of environment. J Exp Biol. 1956;33:29-44.

50. Le Lagadec MD, Chown SL, Scholtz CH. Desiccation resistance and water balance in southern African keratin beetles (Coleoptera, Trogidae): the influence of body size and habitat. J Comp Physiol B. 1998;168:112-22.

51. Tejeda MT, Arredondo J, Pérez-Staples D, Ramos-Morales P, Liedo P, DíazFleischer F. Effects of size, sex and teneral resources on the resistance to hydric stress in the tephritid fruit fly Anastrepha ludens. J Ins Physiol. 2014;70:73-80

52. Chown SL, Klok CJ. Water-balance characteristics respond to changes in body size in subantarctic weevils. Physiol Biochem Zool. 2003;76:634-43.

53. Rozen-Rechels D, Dupoué A, Lourdais O, Chamaillé-Jammes S, Meylan S, Clobert J, Le Galliard JF. When water interacts with temperature: ecological and evolutionary implications of thermo-hydroregulation in terrestrial ectotherms. Ecol Evol. 2019;9:10029-43.

54. Byrne MJ, Duncan FD. The role of the subelytral spiracles in respiration in the flightless dung beetle Circellium bacchus. J Exp Biol. 2003;206(8):1309-18.

55. Duncan FD, Byrne MJ. The role of the mesothoracic spiracles in respiration in flighted and flightless dung beetles. J Exp Biol. 2005;208:907-14.

56. Moretti M, Dias AT, De Bello F, Altermatt F, Chown SL, Azcárate FM, Bell JR, et al. Handbook of protocols for standardized measurement of terrestrial invertebrate functional traits. Funct Ecol. 2017;31:558-67.

57. Rolandi C, Iglesias MS, Schilman PE. Metabolism and water loss rate of the haematophagous insect Rhodnius prolixus: effect of starvation and temperature. J Exp Biol. 2014;217:4414-22.

58. Shapiro-llan DI, Brown I, Lewis EE. Freezing and desiccation tolerance in entomopathogenic nematodes: diversity and correlation of traits. J Nematol. 2014;46:27.

59. Chamberlain D, Tocco C, Longoni A, Mammola S, Palestrini C, Rolando A. Nesting strategies affect altitudinal distribution and habitat use in Alpine dung beetle communities. Ecol Entomol. 2015;40:372-80.

60. Holley JM, Andrew NR. Experimental warming disrupts reproduction and dung burial by a ball-rolling dung beetle. Ecol Entomol. 2019;44:206-16.

61. Holley JM, Andrew NR. Warming effects on dung beetle ecosystem services: brood production and dung burial by a tunnelling dung beetle, Onthophagus taurus (Coleoptera: Scarabaeidae), is reduced by experimental warming. Austral Entomol. 2020;59(2):353-67.

62. Mamantov MA, Sheldon KS. Behavioural responses to warming differentially impact survival in introduced and native dung beetles. J Anim Ecol. 2021;90(1):273-81.

63. Dormont L, Rapior S, McKey DB, Lumaret JP. Influence of dung volatiles on the process of resource selection by coprophagous beetles. Chemoecology. 2007;17(1):23-30.

64. Borghesio L, Palestrini C, Passerin dP. The dung beetles of Parco Nazionale Gran Paradiso: a preliminary analysis (Insecta: Coleoptera: Scarabaeoidea). Hibex J Mt Ecol. 2001;6:41-8.

65. Barbero E, Palestrini C. Aphodius (Coprimorphus) scrutator (Herbst, 1789) descrizione della larva e note di biologia riproduttiva (Coleoptera, Scarabaeoidea, Aphodiidae). Fragm Entomol. 1995;26:341-52.

66. Bertelsmeier C. Functional trait ecology in the Anthropocene: a standardized framework for terrestrial invertebrates. Funct Ecol. 2017;31:556-7.

67. Wright JC, Machin J. Water vapour absorption in terrestrial isopods. J Exp Biol. 1990;154:13-30.

68. Hansen LL, Westh P, Wright JC, Ramløv H. Metabolic changes associated with active water vapour absorption in the mealworm Tenebrio molitor L. (Coleoptera, Tenebrionidae): a microcalorimetric study. J Insect Physiol. 2006;52:291-9.

69. Loru L, Sassu A, Fois X, Pantaleoni RA. Ethyl acetate: a possible alternative for anaesthetizing insects. Ann Soc Entomol Fr. 2010;46(3-4):422-4.

70. Zuur A, leno EN, Walker N, Saveliev A, Smith GM. Mixed effects models and extensions in ecology with R. New York: Springer Science \& Business Media; 2009. 
71. Bates D, Mächler M, Bolker B, Walker S. Fitting linear mixed-effects models using Ime4. J Stat Softw. 2015;67:1-48.

72. Palestrini C, Barbero E, Roggero A. The evolution of the mouthpart structures in the Eucraniini (Coleoptera, Scarabaeidae). Org Divers Evol. 2020;20(3):451-65.

73. Kumar S, Stecher G, Li M, Knyaz C, Tamura K. MEGA X: molecular evolutionary genetics analysis across computing platforms. Mol Biol Evol. 2018;35:1547-9.

74. Webb CO, Ackerly DD, Kembel SW. Phylocom: software for the analysis of phylogenetic community structure and character evolution. Bioinformatics. 2008;24:2098-100.

\section{Publisher's Note}

Springer Nature remains neutral with regard to jurisdictional claims in published maps and institutional affiliations.

Ready to submit your research? Choose BMC and benefit from:

- fast, convenient online submission

- thorough peer review by experienced researchers in your field

- rapid publication on acceptance

- support for research data, including large and complex data types

- gold Open Access which fosters wider collaboration and increased citations

- maximum visibility for your research: over $100 \mathrm{M}$ website views per year

At BMC, research is always in progress.

Learn more biomedcentral.com/submissions 